\title{
The Use of Descriptive Words and Metaphor in Patient and Carer Experience of Palliative Day Care: Secondary Analysis of a Qualitative Study
}

\author{
J. Richardson ${ }^{*}, 1$ and J. Grose ${ }^{2}$ \\ ${ }^{I}$ Faculty of Health and Social Work, University of Plymouth, UK \\ ${ }^{2}$ Peninsula College of Medicine and Dentistry, Plymouth, UK
}

\begin{abstract}
Background: An independent evaluation of changes to the delivery of Palliative Day Services was carried out during 2006-2007 using interviews with service users. The analysis found that the words and metaphors employed by users of services emphasized their emotional response to the changes, and helped to explain their depth of feeling about their experiences, warranting further investigation.

Aim: To conduct a secondary analysis on interview data collected for the Day Services Evaluation Study in order to understand how patients and their carers use descriptive words and metaphor when talking about their experiences of palliative day services.

Methods: Interview transcripts from 40 patients and 8 carers were subjected to secondary thematic analysis. These were read individually and coded where metaphor or descriptive words had been used to emphasize the effect of the illness and the experiences of the Day Services.

Findings: Examples of the metaphorical expressions and words used described the service as a 'secure rock in a changing world'; transition was felt as 'sadness', a 'betrayal', with feelings that the changes were 'bitter and twisted;' and left 'a black hole'. Post transition the mood had changed to acceptance 'When life throws lemons at you, you make lemonade'.

Conclusions: The metaphors and descriptive words used act as what we describe as 'emotional intensifiers' which provide a measure of the impact of the effect of illness, the effect of the day services on users and carers and the intensity of feeling during the time of transition.
\end{abstract}

\section{BACKGROUND}

Specialist palliative day care is defined as services that are provided by specialist multidisciplinary palliative care teams that offer a range of opportunities for assessment and review of patients' needs and enable the provision of physical, psychological and social interventions within a context of social interaction, support and friendship [1]. Research has demonstrated the value of palliative day services in providing respite and support for carers, and space for patients to socialise with others facing similar health, social and emotional challenges [2-4]. Kennett [5] found that day hospice patients valued the emotional care, the sense of community and belonging, and the feelings of achievement they gained from participating in activities such as arts and crafts.

A variety of approaches to delivering day services in palliative care exist. For example, those offering therapeutic interventions more in keeping with a 'medical model', and others that provide a 'social model' where emphasis is placed on supporting social interaction through shared crafts and other activities carried out in groups. However, services need to be responsive, and involve detailed assessment in order to provide appropriate care based on individual needs.

*Address correspondence to this author at the Faculty of Health and Social Work, 19 Portland Villas, University of Plymouth, Drake Circus, Plymouth Devon PL4 8AA, UK; Tel: 01752 586535;

E-mail: janet.richardson@plymouth.ac.uk
During 2006-2007 a hospice in the South West of England redeveloped their Day Services in order to provide specialist palliative care. The management team agreed that the planned service changes (from a day care model to provision of sessions, involving the discharge of some patients) would take the form of a pilot in order that the affects of changes on service users and staff could be evaluated. The UK National Institute for Clinical Excellence (NICE) Guidance on Cancer Services [6] recommendations include the development of new and existing services 'within a rigorous and properly funded evaluation framework' (13.22), and 'studies that measure aspects of services important to users' (13.23). It was in this context that the hospice decided to commission an independent evaluation of the pilot service: The Day Services Evaluation Study [7].

During the process of analysis of the interviews carried out as part of the Day Services Evaluation Study [7] it was found that users of services often used metaphor ' $a$ secure rock in a changing world' or descriptive words such as 'companionship' and 'security' to explain their depth of feeling about the experiences of illness, receiving day care services and the dedication of the staff. These metaphors and words were profound and warranted further analysis. By returning to the transcripts using a qualitative methodology the researchers felt the deeper emotional impact of illness and day care support might emerge. 


\section{THE CHOICE OF QUALITATIVE METHODOLOGY}

Greenhalgh [8] suggests that quantitative research can lose the 'emotional impact' of the story being told. Qualitative research offers an opportunity to find meaning in the words people use to describe their experience. The meaning is discovered using a reflexive approach. As Holloway and Freshwater [9] point out the process of reflexivity demands that the researcher becomes reflective about the reflections of the participants'. This method was therefore suitable for our secondary analysis of transcripts where we were looking for specific descriptive words or metaphors which might enhance the meaning of the experience of changes in hospice day care services.

Metaphor: Alvesson \& Skoldberg [10] define metaphor as 'some kind of correspondence between two different phenomena'. For example using one of our identified metaphors 'a secure rock in a changing world' a rock and a changing world are not similar but in their correspondence suggests how there can be something stable to hold on to which might help to stabilise an unstable environment. Lakoff \& Johnson [11] describe the use of metaphor as a way of grasping emotionally difficult concepts, of finding meaning in intangible ideas. Our interest was in finding if and how metaphors had been used in addition to descriptive words in the transcripts because of a metaphor's particular value in offering insight into how individuals manage an emotionally charged situation at a time of change. By identifying the metaphors patients used to describe their experience we intended to not only hear the patient's voice but also to create empathy in the reader.

It could also be argued that metaphors are both culturally specific (the example used in this research "kicking the illness in to touch' would only be understandable to those who knew the game of rugby) and are also used as culturally available shorthand, thus possibly reducing their impact as a tool for understanding the meaning of emotion. However we believe it is precisely this culturally specific nature which makes them valuable in emphasising the degree of feeling in a given situation.

\section{METHODOLOGICAL ISSUES IN USING EXISTING DATA FOR SECONDARY ANALYSIS}

Unlike quantitative research where data is collected and then analyzed, in qualitative research data emerges as a by product of the relationship between researcher and participant and may be analyzed in a continuous process from the first interview onwards [12]. Secondary analysis of existing data cannot re-create that relationship but recontextualizes the data creating new themes as new understanding emerges [13]. In this way a secondary analysis of existing qualitative data enables an 'alternative perspective on the original question' [14]. A further benefit of secondary analysis is that it offers re-interpretation without further interviewing of the same participants, this not only avoids further intrusion into their lives, but it reduces overall costs and allows extra research time for analysis [12].

Qualitative researchers emphasize the importance of the primary relationship between researcher and participant [15]. A further analysis by another researcher may limit interpretation because of the distancing from the primary relationship. The original context is removed and some of the valuable depth of meaning might be lost. However it could be argued that the majority of qualitative research involves either teams, who share the coding of interviews, or some coding is carried out simultaneously by other experienced researchers to increase validity. Thus the debate about the primary relationship, whilst important, may not detract from the value of secondary analysis. Szabo \& Strang [12] suggest that contact with the original researcher, where possible, is advisable to maintain some of the original flavour of the interviews.

Another issue raised about a limitation of this method is that problems with the original process of data collection or analysis may not be taken into account in this second phase. In this study the secondary analysis was undertaken by a different researcher than the Evaluation Study. However the first researcher was available to discuss any issues of methodology arising from the initial Evaluation Study [7].

\section{AIM}

To conduct a secondary analysis on interview data collected for the Day Services Evaluation Study in order to understand how patients and their carers use metaphorical descriptions and descriptive words when talking about their experiences palliative day services.

\section{METHOD}

Data was collected (by JR) from 40 patients and 8 carers through in-depth group and individual semi-structured interviews from January 2006 - August 2007. This covered the period from the announcement of the service changes to the end of the six-month pilot, and included a number of patients who had been discharged from the service. Ethical approval for the study had been granted by the University Research Ethics Committee and patients were fully informed of the study prior to consenting to participate. Interviews were audio-recorded, transcribed, analyzed and written up as a report for Hospice managers.

This secondary analysis was conducted by a second researcher (JG). However, initially three transcripts were coded by both the first and second researcher. This enabled comparison of coding between the researchers and a better understanding of what would be chosen as descriptive words or metaphors. The framework for the analysis is provided by Lakoff \& Johnson's approach to understanding meaning by the use of metaphor [11].

The transcripts were read individually and coded where metaphors or descriptive words had been used to highlight the effect of the illness, experience of the service, and transition. A second reading of the transcripts studied these further and related them to the context in which they were used. During this stage of the analysis we found four distinctive themes, 'what it's like to be ill'; 'the centre/hospice', 'transition' and 'post transition'.

When presenting the data below we have not provided a specific patient/carer reference when many participants used the same word. However where longer quotations are presented, reference to the transcript and line number from 
which it came has been used: $\mathrm{P}=$ patient; $\mathrm{C}=$ Carer; $\mathrm{Gr}$ =group.

\section{RESULTS}

Themes generated from the secondary analysis of the interview data were

- What it's Like to be Ill

- The day hospice

- Transition

- Post Transition

Theme One: 'What it's Like to be Ill'

Participants used a variety of words to describe their experience of a life-limiting diagnosis: knocks, overwhelms, changing, disappear, withdraw, loneliness, loss. These words reflect the loss of control over their lives and the feelings of vulnerability which then recur during the course of the disease.

One participant used a metaphor to explain how they managed their lives despite being ill:

'..you kick your illness into touch and get on with your life'. ( $\mathrm{P} / \mathrm{C} 3$ 498).

The idea of kicking creates a picture of a muddy rugby ball being kicked over a line so the game (of life) can continue, putting the illness firmly in its place.

It was dealing with other people's perceptions of them as an ill person that they often found hard to manage. The following words provide an idea of the emotional response of others towards people who are unwell: 'contagious'; 'fuss'; 'ignore'; 'afraid to touch'; being judged'; 'they look as though you are stupid'. The illness creates feelings of being removed from the 'normal' way of life.

\section{Theme Two: 'The Day Hospice'}

The participants used a variety of words to describe their experience of coming to the Day Hospice. In theme two the descriptive words are subdivided into the effect of the place/context, the sharing during lunch, the relationships with other patients, the impact on carer, and the users' relationships with the staff. Key words in this context were 'time' which they used to describe the amount of time the staff were willing to give them and also how time changes with illness. Time at the Day Hospice was valued because it provided an opportunity to quietly reflect and seek guidance within a context where patients were running out of time as their illness progressed. Another key descriptive word which occurred repeatedly was 'security'. Patients felt the Day Hospice provided a sense of security they could not experience outside. Carer felt they could leave their partners in safe hands and the emotional and physical security of the hospice itself meant they could enjoy respite from caring without feelings of guilt or anxiety.

One participant commented:

'I think all hospices have a special X factor.' (P/C 3 437).

It was in trying to explain the concept of the $\mathrm{X}$ factor that participants attempted to describe, by using a metaphor, what a day hospice meant to those requiring palliative care: 36).

'A secure rock in a world that's constantly changing' ( $\mathrm{P} 1$

This metaphor of a rock suggests solidity, something that can be relied upon for its strength, something to lean against. Some used other metaphors to try to describe the mix of activities which supported the essence, the $\mathrm{X}$ factor of the place:

'It's very difficult, if you think of a cocktail made up of many ingredients, when you're sampling the cocktail it's the cocktail isn't it? You may pick out the particular flavour in the cocktail and comment upon it, but in essence it's the ingredients that make up the whole, and that's the same with this place. It's got so many different facets which come together; some are more obvious than others' (Gr1 168).

Others used a variety of words which offered an insight into how they responded emotionally to coming to the hospice: 'a haven' 'wonderful'; 'amazing;' 'comfortable'; 'lovely;' 'good'; 'another world'; 'tremendous'; 'therapeutic'. The intensity of these words suggests the degree to which users felt part of the day hospice and also the degree to which the staff and activities had positively affected their lives. Possibly the most poignant of the more unconscious use of metaphor was that at the hospice patients were 'spoilt to death'.

During the course of the analysis it emerged that meeting together for a meal developed a sense of communion. It was an opportunity for fun, for mutual support, and sharing. One participant suggested it was:

'.. The kind of cement that holds the whole thing together' (P/C 4 345).

This sense of being bound together (cement) recurred often and increased the understanding of how individuals valued the experience. Some patient's needed to have a meal because they did not cook for themselves at home, but for the majority it was the sharing and relaxing that formed the friendships and created a sense of 'family'.

One of the potential problems identified by patients about the move to session based care was the possible reduction in this informal emotional support offered between and amongst users. This was seen as very important to patients because of their decreasing role in family life and reduced community involvement outside the Hospice. The word 'family' occurred many times it suggests that service users created a new family where sharing troubles increased a sense of status and made them feel worthwhile. This sense comes from words such as 'life enhancing'; 'bond'; 'companionship'; 'sharing stuff'; 'comradeship'. The sharing was possible because they felt 'the same', as other users. There was a 'bond' and sense of 'value.'

Carer groups were well attended and carers continued to meet after their relative had died in order to support each other through the changing roles and losses. One carer described the experience of caring for a loved one with a life limiting illness as:

'I likened at a meeting I attended once the journey of a carer with somebody who, as xxx is, got a long term chronic condition. It's like taking a train journey from Penzance to Edinburgh except they black out all the windows and you 
know you're on the journey and occasionally it will stop but you don't know where you are and you don't know whether the next stop is going to be the last stop, but you know you're actually making that journey and (pause) just occasionally there may be little chinks of light coming into that but often it's not. It's you're in and you know the train has set off and that's it and ultimately it will arrive at Edinburgh. But the upside, with us kind of ending our conversation on a fairly low note, from my own perspective going through that journey what I do know that, if you like using the analogy of arriving in Edinburgh, there will be people here who will not only understand the journey I've just taken but will support me beyond, and that's a value which you can't put down on any little piece of paper' (C4 586).

This metaphor has value because it suggests both the journey through illness and the role of the carer who is willing to walk alongside the patient whilst neither of them have any idea of the length or quality of the journey. The lack of information about prognosis and possible adverse events is described here by the 'blacked out windows', the comfort for the carer was that at journey's end there would be people in the hospice who understood the experience of the journey, and were able to provide empathy and support.

The carers described the effect on their lives of being able to leave their family members in the Day Hospice as 'biggest support I ever had'. The word 'safe' occurred time and time again and mirrored the frequent use of the word 'security' used by the patients.

The staff working in the Day Hospice were seen as an essential part of the lives of the users, they appeared to have an unspoken understanding of individual needs and were very different from health and social work staff they met in other services. The metaphor of cement was used once again:

'They're very much part of the cement...they provide the structure they are the organization'. ( $\mathrm{P} / \mathrm{C} 4365)$.

Again the word 'time' was used to describe the value of being in an environment where the users need not be rushed to explain how they felt. The staff were 'wonderful' 'supportive' and 'reassuring' they 'won't panic or disappear'. For some, having experienced negative responses from people outside the Day Hospice the fact that the staff knew how to use touch when appropriate was recognized 'it means so much' as a physical response to an emotional need.

\section{Theme Three: 'Transition'}

The metaphorical expressions and words used to describe the experience of moving from one system of care to another spoke not just of the emotional impact on users but also of its effect on the staff they trusted and their feelings about what the new system might offer. However some had recognized that change was inevitable. The contrast between the words used to describe the centre 'wonderful'; 'a haven'; 'another world;' and the words used to describe the response to change 'sadness', 'betrayal', 'bitter and twisted;' 'a black hole'; serve not only to highlight the degree of distress caused by the possibility of change but also to re-emphasize the depth of feeling of the users about the service the hospice provided in their lives.
The process of transition had 'upset the balance' of the daily routine. The initial negative reaction to the news of a possible change occurred because the first letter communicating the changes was poorly understood. This caused a general anxiety which increased because of a 'Chinese whisper syndrome'. This expression was used to describe how information was passed from one person to another and how it became changed in nature thus leading to an 'air of disillusionment'. Many of the participants in the study said 'we're in the dark' this metaphor was developed further by others who described the darkness as 'a black hole'.

As time progressed and the changes began to occur participants had 'a feeling of betrayal' and an 'air of sadness'. Many talked about the feeling of being 'in limbo'. The word limbo suggests the feeling of being between two worlds and not knowing what the future holds. One participant said the news was like:

\section{'Someone else closing a door on your life'. (P/C3 15).}

The users were concerned for the staff. They noticed a 'change of attitude' amongst the staff who they described as having a 'long face', now being 'too busy' to spend time with them as though they were 'pulling back already', which was experienced as 'unsettling'; staff seemed 'sad'.

For some, the changes meant that they returned to the feelings of loss of power they had at diagnosis, and experienced the sense of loss that occurred during the change process and the 'anger' and 'uncertainty' about future roles. Users felt disempowered:

'we are a weak minority of people pleading for something that ain't going to happen, so I give my opinion and lay back and just wait for the disaster to happen. It's very sad but you know.' (P/C2 173).

The metaphor of the 'weak minority' suggests the impotence of people who are ill and a power struggle they did not feel they had the energy to enter into.

What was also important was the perception that the Day Hospice might lose something by changing. The metaphor 'distillation' suggests a watering down of the essence of the place, the essence being the interaction between and amongst the individuals who work in, and attend the day hospice. By using the word 'layers', the idea of deep undercurrents emerges and the effect of the changes would not therefore be superficial but would more likely be deeply felt:

'...but it's something that happens here easily, and it's very difficult, it's the distillation of it all, you know the layers of it all, and they're all essential to make up the whole, there's not one - you take the human beings out of this place and all you've got is bricks and mortar in a nice setting. But it is the human beings and their interaction with each other, the professional staff, patients, carers, it's that interaction, that mix that works well now' (P/C4 531).

There were mixed responses to the idea of a session based service (service users attending for specific time-table sessions, rather than for the whole day). Several respondents suggested that sessions would 'limit your horizons' suggesting a foreshortening of the holistic care that they felt had been previously offered thus 'casualising the service', 
the use of the word casual here possibly suggesting that it would be seen as of less importance.

However some respondents recognized that change was inevitable 'it's the nature of things' and we 'must give to other people I suppose', 'It's just one of those things in life'. It would have been interesting to explore further whether this acceptance of change came from having been diagnosed with a life-limiting illness which led to recognition of the role of fate in life, or, whether it came from a genuine belief that change could be an enhancer of service provision.

Theme Four: 'Post Transition'

A number of participants were interviewed again between 3 and 6 months post transition to assess whether and how the transition process had concluded for them. The memory of the last visits to the Hospice for those who were discharged was still on some peoples' minds. The following provides a metaphorical picture of packing up and moving on:

'... actually it's strange, we had the last day there and all of a sudden the day was over. It all went so quickly. And we were going out of the door and people were being loaded onto their - in their various transport, and suddenly thought, 'Oh! Won't see them again'. And I suppose it was like that for lots of people really. Then that was it. (2P/C3 199).

Those that were changing services altogether expressed their grief by questioning why they were going. The metaphor here 'getting at us' suggests being chosen for discharge because 'we're not dying':

'You know we felt as though we weren't wanted anymore. You know it feels awful when you're - we weren't wanted why, we haven't done anything wrong, we're still ill. I did understand the reason but we didn't at the time. You know what I mean it just felt as though they were getting at us because we're not dying'. (2P12 278).

But as participants moved on they began to become accustomed to their new services either by joining a new group at a different centre or by becoming involved in the new session-based service at the Hospice. The metaphors and descriptive words used about the new environments had echoes of those used to describe the old Day hospice service 'wanting for nothing' and 'companionship':

'We were surprisingly impressed....... In fact it's better because they are more into us... we want for nothing, so it's good' (2P/C8 53).

However those involved in one new service felt anxious that if it was not well attended this too might be taken away, suggesting that the vulnerability created by being removed from the day hospice had continued. The repetition of the word 'hope' and the wandering nature of this narrative suggest a minor anxiety about the permanence of the new service:

'Let's hope this other one keeps it up. I hope it will. I gather they've got to more or less keep 13 to make it viable, which is, you know I can understand that, so, but I think the maximum they're allowed is 15 at the moment so it doesn't give them much flexibility. At least there will be 15 or 13 there now if these three new ones come. I think most of us are there fairly regular, you know suddenly you're not there, summer holiday or somebody's ill or something like that, but in general there's usually - I think it's been down to eight one day down there, now there's a couple more that will be better'.(2P10 281).

As time went on there was recognition that those who were residents in the care home where one of the new services had been set up had been generous in their welcome, 'letting us into their home' suggests the warmth of the welcome and acceptance. The new service members began to feel a responsibility towards their new friends, the possibility of not going 'would be a let down for them'. There was recognition that the joint sessions between new members and the residents had mutual value:

'They live in, they're resident, and in the day room we've noticed now there's half a dozen in particular that keep coming into the day room while we're there, 'cos they hear us bantering between us and having a bit of a laugh and $a$ giggle. Some of them will join in and have a chat but they can't communicate that well some of them, so they will just listen. If you look around they're having a laugh, and I feel to stop going there would be a let down for them......so you know they've let us into their home but I feel that now because they're joining in it's doing them a bit of good as well as us. I hope it is anyhow. They've let us into their home' (2P10 47).

As the old Day Hospice service adapted to a session based service those who had remained had time to reflect on the process of transition. The anger was described as 'perceived' which highlights that on reflection some people may have felt the degree of negative response to the changes had, in some cases been inappropriate. Overall the general mood was positive and was summed up by one couple saying:

'It's been resolved, I think for most people better than we all thought' (2P/C3 217).

Those in the new services, away from the original hospice, also recalled their response to change with some sense of discomfort using words such as 'guilty' and 'feeling sorry':

'I felt a bit guilty putting pressure. And I felt a bit sorry for them (the staff) sometimes' (2P/C8 278).

Whilst recognizing that the process of transition had had some problems, the new positive outlook was succinctly represented by the metaphorical expression:

'When life throws lemons at you, you make lemonade' (2C3 609).

A new session called 'My story' had been particularly successful with patients describing how they were leaving a 'legacy' for their families by preparing memory boxes and DVD's. In the following quote a husband reflects on how the DVD he is preparing will be used after his death. The use of the word 'warm' here offers hope that the DVD will offer comfort, that his wife can 'shut the door' and have a special time with her husband and also that the DVD is a gift to the family 'It will all be there':

'I said to (wife), 'If you ever get upset you just put it on. It will probably make you more upset. But it's warm. You can put it on. You can shut the door. You can get a glass of 
wine, or a bottle of wine, and put on the DVD.'. I would like that. wife can put it on and be with someone for five minutes. And the family and the kids can watch it, and they can show it to the grandchildren. It will all be there. And it was a very, very positive experience.' (2P9 114).

For those attending the sessions the words used were the same as before the changes, describing the 'warmth' 'companionship' and 'tranquillity' which provides a safe environment for the patients and their carers. One patient used the metaphor:

'Death with air freshener' (2P13 247).

Others used the metaphor of 'a sanctuary' emphasizing the security offered away from an outside world that sometimes seemed hostile and frightening.

The participants in the last stage of this study appeared to have moved on past the traumas of transition. They had the opportunity to reflect and synthesize their experience. They concluded the new session-based service at the hospice still offered the same sanctuary for all. The following description uses a metaphorical story of the behaviour of the badgers in the garden. If the badgers felt safe enough to come out during the day then the essence of the hospice had survived the transition:

'.... during the day, a young badger...... he came out and started playing ..... while we were having lunch. That probably shows you how nice the place is. A lot of animals wouldn't come out. And the amount of birds that come down and land while you're out there. It's really like something out of Mary Poppins. It's really sweet and natural. (2P9 $585)$.

\section{DISCUSSION}

This study identified the descriptive words and metaphors patients and carers had used during their interviews as part of a Day Hospice Evaluation Project [7] in order to understand the degree to which they had been affected by the changes. The descriptive words and metaphors presented in the results section were intended to highlight the intensity of experience caused by the change to the service and how those involved eventually resolved their feelings and moved on.

This method of identifying the descriptive words and metaphors moves away from traditional categorizing of qualitative research to an approach more akin to discourse analysis [9]. By using this method it is possible for the researcher to decide where the greatest emotional impact of the changes was experienced and this in turn can inform both immediate solutions and future plans for organizational change.

The limitations of using secondary analysis were largely ameliorated by the first and second researcher working together, keeping the voice of the participant alive and cross referring to avoid loss of the original context [10]. In addition, the secondary analysis was conducted sequentially allowing little time to have elapsed between data collection and secondary analysis, thus maintaining the context of the primary research, the Day Hospice Evaluation Project [7].

The results of this analysis are echoed in other research which considered the value of palliative day service provision. A qualitative study gathering patient feedback from semi-structured questionnaire data [16] found that patients were 'very appreciative' of this form of care however we considered whether the level of enthusiasm found in the current study might also be related to 'concern for the continuance' of services. This anxiety over possible change in existing services needs to be well managed by hospice staff prior to change being introduced.

Researchers exploring the experiences of people involved in UK palliative care services [17] found that patients reported an improvement in their quality of life and general self esteem. This current study has provided evidence which suggests that metaphors are a valuable method of understanding the depth and intensity of feeling. One of the participants described the last phase of life as a journey on a train. In a study involving nurses this metaphor was also used when describing the meaning of palliative care for people with life threatening diseases [18]. The nurses characterised the metaphor of the train journey by the three themes 'transit points, time and guidance'. The value of the nurse/patient relationship in sharing the journey was highlighted and was reiterated here when participants talked about nurses as being the 'cement that holds the whole thing together'. However our study suggests that it is the mutual support of carers, staff and other patients that keeps the train on the tracks and makes the journey as bearable as possible.

\section{FUTURE RESEARCH}

\section{Secondary Analysis}

Literature on the benefits and limitations of using secondary analysis in qualitative research, although growing, is still insufficient. This approach was seen here to have value in re-contextualizing the data and creating a greater depth in understanding of the experiences of the participants. Secondary analysis can reduce the burden of data collection and research fatigue on patients, in particular those with chronic or life-limiting illness. Furthermore it can be of particular benefit for students learning qualitative analysis.

\section{Use of Descriptive Words and Metaphor}

Analysis of descriptive words and metaphor has provided a purpose and context for the secondary analysis allowing a new approach to understanding these data and offering a greater focus on emotion, assumption and depth of feeling at a time of transition. The value of this method has been recognized here but further adaptation of this method of analysis of qualitative studies would raise the profile of this useful tool.

\section{CONCLUSION}

Of importance in this study and in others [16, 18, 19] is that there is high satisfaction amongst users of palliative day services and that there is a subjective feeling of improvement in quality of life. What is less clear is the role day care plays in symptom control or whether the costs outweigh the benefits of providing day services. What this study has shown is the intensity of feeling about the value of palliative day services and the need for careful management of patients and carers at times of transition of focus and/or care provision. The study is limited by the fact that some service users were being discharged due to the service changes so 
may have over-emphasised the service benefits in their interviews.

\section{REFERENCES}

[1] National Council for Hospice and Palliative Care Services. [Accessed 20 April 2009]. Available from: http://www.ncpc. org.uk/palliative_care.html

[2] Hopkins JB. A study of the perceptions of hospice day care patients: my phenomenological methodology. Int J Nurs Stud 1999; 36:203-7.

[3] Hopkins JB, Hallett CE. Patients' perceptions of hospice day care: a phenomenological study. Int J Nurs Stud 2001; 38:117-25.

[4] Lawton J. The dying process: patients' experiences of palliative care. London: Routledge 2000.

[5] Kennett C. Understanding why palliative care patients "like day care' and 'getting out'. J Palliat Care 2005; 21:292-8.

[6] The National Institute for Clinical Excellence (NICE) Guidance on Cancer Services. NICE 2004. [Accessed 12 Feb 2005]. Available from: http://www.nice.org.uk

[7] Richardson J. An evaluation of service changes within a day hospice setting (unpublished draft report) 2008.

[8] Greenhalgh T. How to read a paper: the basics of evidence based medicine. London: BMJ Books 2001.

[9] Holloway I, Freshwater D. Narrative research in nursing. London: Blackwell Publishing 2007.
[10] Alvesson M, Skoldberg K. Reflexive Methodology: new vistas for qualitative research. London: Sage Publications 2000

[11] Lakoff G, Johnson M. Metaphors we live by. London: University of Chicago Press 1980.

[12] Szabo V, Strang V. Secondary analysis in qualitative data: methods of clinical inquiry. ANS Adv Nurs Sci 1997; 20(2): 66-74.

[13] Moore N. (Re) Using Qualitative Data. Sociological Research Online. 2007; Vol. 12(3). [Accessed 2 Mar 2008]. Available from: http://www.socresonline.org.uk/12/3/1.htm

[14] Heaton J. Secondary analysis of qualitative data. Social Research Update 1998. [Accessed 3 Mar 2008]. Available from: http://sru.soc.surrey.ac.uk/SRU22.html

[15] Nankoosing K. The problems with interviews. Qual Health Res 2005; 15(5): 698-706.

[16] Low J, Perry R, Wilkinson S. A Qualitative evaluation of the impact of palliative care day services: the experiences of patients, informal carers, day unit managers and volunteer staff. Palliat Med $2005 ; 19,1: 65-70$

[17] Hjelm E, Hartig K, Bertero C. An inevitable journey by train: nurses' narratives about palliative care. J Hosp Palliat Nurs 2007 9, 4: 206-11.

[18] Kernohan WG, Hasson F, Hutchinson P, Cochrane B. Patient satisfaction with hospice day care. Support Care Cancer 2006; 14 462-8.

[19] Davis E, Higginson IJ. Systematic review of specialist palliative day-care for adults with cancer. Supportive Care Cancer 2005; 13: 607-27.

(C) Richardson and Grose; Licensee Bentham Open.

This is an open access article licensed under the terms of the Creative Commons Attribution Non-Commercial License (http: //creativecommons.org/licenses/by$\mathrm{nc} / 3.0 /$ ) which permits unrestricted, non-commercial use, distribution and reproduction in any medium, provided the work is properly cited. 